\title{
A global landslide catalog for hazard applications: method, results, and limitations
}

\author{
Dalia Bach Kirschbaum • Robert Adler • Yang Hong • \\ Stephanie Hill · Arthur Lerner-Lam
}

Received: 9 January 2009/Accepted: 16 April 2009/Published online: 10 May 2009

(C) The Author(s) 2009. This article is published with open access at Springerlink.com

\begin{abstract}
A systematic inventory of landslide events over the globe is valuable for estimating human and economic losses, quantifying the relationship between landslide occurrences and climate variations and for evaluating emerging global landslide prediction efforts based on remote sensing data. This study compiles a landslide catalog for rainfalltriggered events for several years, drawing upon news reports, scholarly articles, and other hazard databases to provide a landslide catalog at the global scale. While this database may only represent a subset of rainfall-triggered landslides globally, due to lack of reports, it presents a lower boundary on the number of events globally and provides initial insight into the spatiotemporal statistical trends in landslide distribution and impact. This article develops a methodology for landslide event compilation that can be used in evaluating global landslide forecasting initiatives and assessing patterns in landslide distribution and frequency worldwide.
\end{abstract}

D. B. Kirschbaum $(\bowtie) \cdot$ A. Lerner-Lam

Lamont-Doherty Earth Observatory, Department of Earth and Environmental Sciences,

Columbia University, 61 Route 9W, Palisades, NY 10964, USA

e-mail: dbach@1deo.columbia.edu

R. Adler

NASA Goddard Space Flight Center, 8800 Greenbelt Road, Greenbelt, MD 20771, USA

R. Adler

ESSIC, University of Maryland College Park, 2207 Computer and Space Sciences

Building (\#224), College Park, MD 20742, USA

Y. Hong

School of Civil Engineering and Environmental Sciences, National Weather Center, University of Oklahoma, 120 David L. Boren Blvd., Suite 3642,

Norman, OK 73072, USA

S. Hill

Department of Geography, East Carolina University, Brewster Building A-227, Greenville, NC 27858, USA 
Keywords Landslide database $\cdot$ Rainfall-triggered landslides $\cdot$ Global event inventory

\section{Introduction}

While natural hazards such as hurricanes or earthquakes, which affect large spatial extents, have global catalogs of hazard frequency and losses, few inventories have been developed for smaller hazards such as landslides. A global catalog of landslide events can be valuable for a number of purposes, including estimation of human and economic losses, quantification of the relation of landslide statistics to seasonal and climate variations such as El Nino South Oscillation (ENSO), and evaluation of emerging global landslide prediction efforts based on remote sensing data. Despite limitations in inventory completeness, a systematic approach to data compilation is urgently needed, which should incorporate as much accuracy as possible with respect to the location, event size, timing, and human and economic impact. Previous landslide inventory studies have been motivated by engineering questions and development projects at the slope or watershed scales (Crozier and Glade 2006). The small areas considered for these studies are based on the availability of high resolution aerial photography data and surface validation. These studies are frequently limited by the time, expense, accuracy, and subjectivity involved in defining and compiling landslide events (van Westen et al. 2006). As a result, landslide inventories are principally used to develop landslide hazard and susceptibility analyses over very small extents.

While several research initiatives have compiled inventories at the national (Castellanos Abella and van Westen 2007; Chau et al. 2004; Guzzetti et al. 1994) and global (Petley et al. 2005) scale, these studies constrain the search criteria for cataloging landslide events by region, event type, or landslide impact. This study outlines a methodology to catalog landslide events at the global scale systematically. The technique uses written media, including literary and scientific news sources and real-time reporting to develop a new, empirical global catalog of rainfall-triggered landslide events that can be used to consider landslide distributions at larger spatial scales as well as evaluate global and regional landslide hazard analyses.

The primary motivations for compiling a global landslide inventory are to approximate the spatial and temporal trends in landslide occurrences on the global scale and to use the database to evaluate a preliminary global landslide hazard algorithm developed by Hong et al. (2006, 2007). The algorithm integrates surface information and multi-satellite rainfall data to obtain estimates of areas susceptible to landslides globally. The forecasts made by the algorithm require clear, well-categorized landslide event data to test the relative skill of the algorithm as well as to determine how model constraints should be adjusted for better performance. Kirschbaum et al. (2009) provides an evaluation of the global algorithm's performance accuracy and relative skill. The inventory considers all the available rainfalltriggered landslide and debris flow events using reports from governmental and non-governmental (NGO) reports, relief aid organization information, academic papers, and newspaper articles. This study presents an overview of the current work in this area, outlining the requirements for such a catalog and the limitations in compiling a database at the global scale. We describe the methodology used to compile the global landslide catalog and present results on the spatial and temporal distribution of landslide reports and fatalities for the years 2003, 2007, and 2008. Finally, the study discusses the utility of this global landslide catalog and the potential usages for such an empirical database in the future. 


\section{Conceptualization and compilation of a landslide database}

\subsection{Current landslide research}

The majority of landslide inventory work has focused on smaller area investigations, developing local or regional maps that outline the locations and characteristics of landslides in a designated area. These studies rely on multi-temporal aerial photograph interpretation or remote sensing data and field validation to derive maps for landslide events. The maps can provide detailed information on landslide features over small areas and can be used for deterministic slope stability or multivariate statistical analyses (Baeza and Corominas 2001; Baum et al. 2002; Iverson 2000). While valuable, these inventory maps usually do not provide information on the timing of the events, making it difficult to correlate landslide occurrence with specific triggering events. The process used for developing a landslide map can also vary significantly based on the methodology and expertise of the scientists conducting the study (Ardizzone et al. 2002; Guzzetti et al. 1999).

Landslide inventories compiled using news reports and other media sources have been performed at the national scale or global scale. The AVI project, a study undertaken by the National Group for Prevention of Hydrogeologic Hazards in Italy, used newspapers, technical and scientific reports, aerial photographs, regional topographic maps, and expert and eyewitness interviews throughout the country to compile a national flood and landslide inventory for Italy (Guzzetti et al. 1994). This effort represents one of the most extensive records available at a national scale, but unfortunately few other countries have developed such initiatives. The International Landslide Centre (ILC) at the University of Durham is currently conducting one of the only other global landslide inventory studies. This group has drawn on a wealth of news reports, academic papers, government and aid agency reports, and personal communications to compile an inventory of landslide events that have caused fatalities on the global scale. The ILC has been collating a database since September 2002 and is working to evaluate patterns in landslide fatalities at the global and regional scale (Petley et al. 2005, 2007).

The catalog compiled for our study includes all landslide events that are clearly triggered by rainfall conditions. The catalog considers all types of landslide events from shallow debris flows to deep seated complex rotational slides. We use 'landslide' as a general term to represent all event types, although the catalog differentiates between landslide types when the information is available. Since it is often difficult or impossible to distinguish specific landslides triggered by the same extreme rainfall event over the same area, we use the term 'event' to refer to either a single landslide or a grouping of landslides and consider it as a single entry.

\subsection{Sources for landslide entries}

In order to catalog a landslide in the inventory, there are several primary elements required to describe the event and secondary elements, which provide additional information about the landslide characteristics, when available:

\section{Primary elements}

1. Nominal location information (town/village, county, province, country)

2. Time (date and local time of event)

3. Trigger (rainfall) 


\section{Secondary elements}

4. Type and relative size of the event (e.g., landslide, debris flow, mudslide, rock avalanche; size is specified using a qualitative index described below)

5. Latitude and longitude (with an indication of the location accuracy)

6. Impact information (e.g., fatalities, injuries, affected infrastructure, economic damage)

The primary and secondary elements for each landslide event were obtained mainly from online news media, links to reported landslides in newspapers, and hazard databases, including: International Consortium on Landslides website (ICL; http://iclhq.org); International Landslide Centre, University of Durham (ILC; http://www.landslidecentre.org); The EM-DAT International Disaster Database (http://www.em-dat.net); International Federation of Red Cross and Red Crescent Societies field reports (http://www.ifrc.org); Reliefweb (http://reliefweb.int); humanitarian disaster information run by the United Nations Office for the Coordination of Humanitarian Affairs (OCHA); other online regional and national newspaper articles and media sources.

There are several other websites providing web links to media reports of landslide events regionally and globally, which can serve as additional resources for updating the landslide event catalog. The Geological Survey of Canada provides a monthly updated list of online news reports and brief synopses of landslide events worldwide (http://gsc.nrcan. gc.ca/landslides/in_the_news_e.php). At present, the website provides hyperlinks to event reports occurring within the past 3 months. The news reports posted on this website were cross-checked with the 2007 and 2008 landslide inventory events and were helpful for identifying additional landslide events or corroborating existing landslide event information. The United States Geological Survey (USGS) Landslide Hazards Program offers two repositories for landslide inventory information; one that provides hyperlinks to news reports of global landslide events chronologically (http://landslides.usgs.gov/recent) and the second website that posts links to regional digital landslide inventories, susceptibility analyses, and additional landslide information within the continental United States (http:// landslides.usgs.gov/regional/inventory). One limitation of providing hyperlinks to relevant news articles is that frequently older online news article hyperlinks have been deactivated, making it challenging to obtain information from the referenced articles and compile landslide events retrospectively. As a result, these websites serve as good references for identifying landslides reported in the global media but are most accurate within the past few months to one year of when the landslide report is issued.

\subsection{Landslide database compilation}

Online news articles serve as the primary sources of information for the landslide catalog and are found using Google Alerts (http://www.google.com/alerts) and other search engine options. When possible, multiple sources are consulted for redundancy. The primary and secondary elements describing the landslide event are cataloged in a spread sheet. The latitude and longitude of the landslide event is then approximated using Google Earth (http://www.earth.google.com) and other map search websites (Falling Rain Genomics, http://www.fallingrain.com/world; National Geospatial-Intelligence Agency, http://geonames. nga.mil/ggmagaz/geonames4.asp). In many cases, large uncertainties exist when assigning geographic coordinates to a landslide event, especially where multiple landslides or affected areas were referenced in one report. To account for uncertainty in event location, we assign a radius of confidence (in kilometers) to the location, indicating the potential 
radius over which the landslide may have occurred (Table 1). From the radius of confidence value, we have developed a qualitative Location Classification index to define the general location accuracy of the landslide event on a scale of 1 (little confidence in the landslide location) to 5 (location known within a $5 \mathrm{~km}$ radius). A landslide location classification was assigned to each landslide entry, and distributions are shown in Fig. 1. The precision of the radius of confidence ranges from 0.5 to $20 \mathrm{~km}$ depending on the information available within the landslide reports. The time precision accuracy is usually within $24 \mathrm{~h}$ of the date listed in the inventory, unless the entry represents an unknown number of landslides occurring during a multi-day rainfall event. During such an event, the day corresponding to the start of the landslide series is listed.

A size classification was developed to obtain an estimate for the relative extent of each event and is described in Table 1. Most news reports lack information on the volume or aerial extent of the landslides; therefore, we assume that larger landslides will impact larger areas and use information on the reported extent of landslide impact to differentiate minor events from catastrophic incidents. The events were classified on a scale of 1 (a landslide that affected one small slope) to 5 (a landslide or series of landslides that affected multiple villages or a region and caused numerous fatalities). The distribution of this qualitative index for the 3 years of available data is illustrated in Fig. 1. This qualitative index was specifically developed to provide additional information when evaluating the global landslide hazard algorithm but may also be helpful when no other information on landslide size is available.

The last columns of the landslide catalog describe the type of landslide, if specified, the source from which the information was taken, and fatality or injury estimates. Any other information on the landslide impact is also documented, including the time of the landslide and type of rainfall event which was thought to have triggered the landslide as well as any other event information. Landslide catalogs have been prepared for 2003, 2007, and 2008. The 2003 catalog was developed using an initial landslide database available from the International Landslide Centre (ILC), and was updated with additional news report and database information. The landslide cataloging project began in June 2007 and was continued throughout 2008. Landslide data for 2003 and the early half of 2007 were obtained retrospectively from the websites listed in Sect 2.2. Table 2 shows an example of the landslide entries in the catalog from the beginning of July, 2007.

\subsection{Landslide catalog uncertainty}

It is extremely challenging to compile a global catalog of landslide events due to limited data availability and heterogeneous reporting at this scale. Consequently, the landslide database is severely limited in its accuracy and completeness. Variations in landslide reporting frequency and accuracy represent the most challenging and unquantifiable component of this study. This problem is consistent with similar studies that find substantial heterogeneities in landslide reporting, documentation, and reliability of size and impact estimates (Castellanos Abella and van Westen 2007; Chau et al. 2004; Guzzetti et al. 1994; Petley et al. 2005, 2007).

Four main problems exist in compiling an inventory based on unmapped events. First, the study considers all rainfall-triggered landslide events globally and therefore will underestimate the number of actual landslide events, particularly in remote areas. Second, there is extensive misreporting of landslide events because landslides are often grouped with primary triggering hazards such as floods, tropical cyclones, and flooding. As a result, fatality estimates and location information for the landslide events are almost impossible to distinguish from areas severely affected by the other hazards. This causes a bias when the 


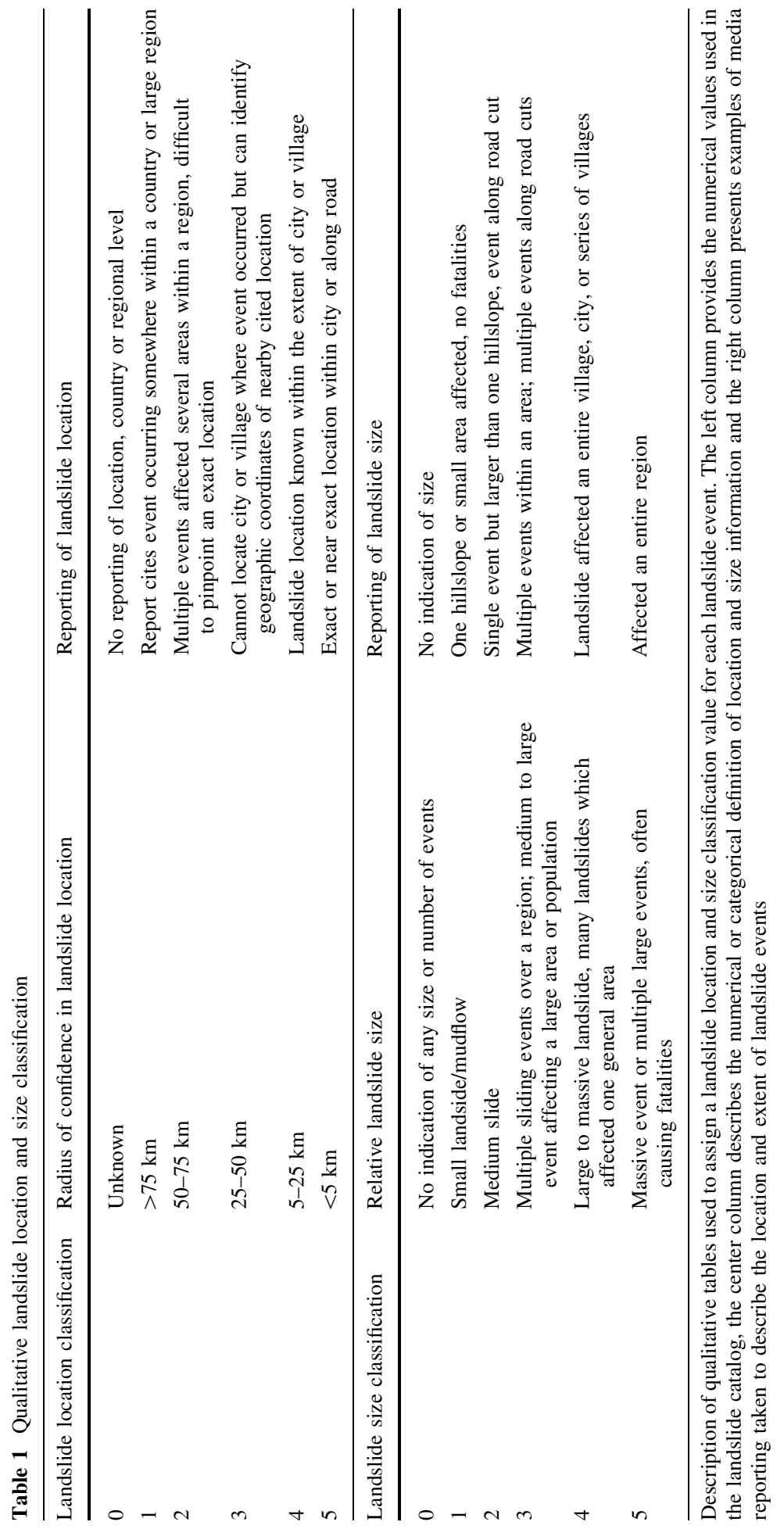


Fig. 1 (a) Location classification and (b) size classification distribution for the 3 years of the landslide catalog
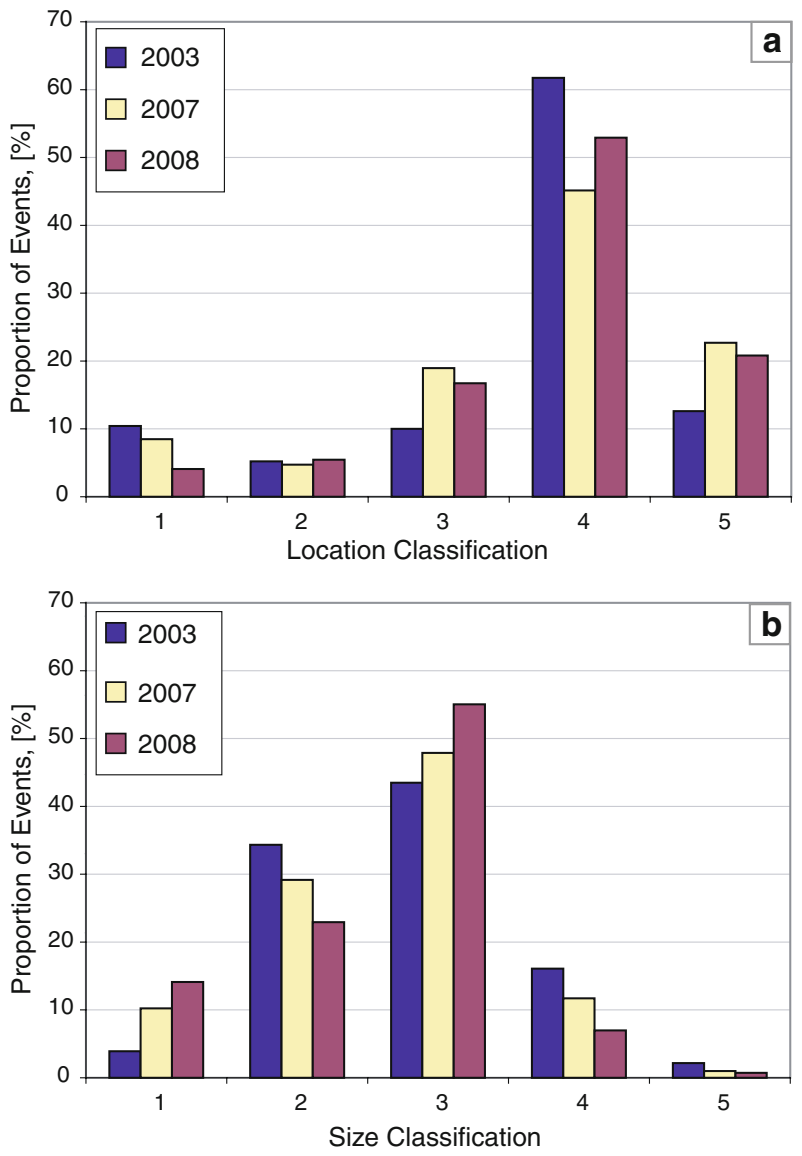

more devastating disaster is reported and often results in an under-reporting of landslide events (Guzzetti 2000). In addition to hydrological triggers, slope instability and subsequent landslide activity may also result from tectonic and anthropogenic disturbances. Extreme rainfall triggered tens of thousands of landslides in the Wenchuan region of China following the devastating $M_{\mathrm{w}} 7.9$ earthquake in May, 2008 (Marui and Nadim 2009). Anthropogenic modification of hillslopes can also serve to intensify the propensity for landslides during or subsequent to extreme rainfall events, occurring when the natural basal support structures are removed as a result of road cuts, devegetated slopes, and development in marginal areas (Diaz 1992; Haigh et al. 1995; Larsen and Parks 1997). In these cases, multiple triggering sources may be responsible for the landslide events, which complicate the accurate identification and characterization of these hazards.

A third source of uncertainty results when news reports do not specify the number of landslides in a particular area or triggering event, nor do they offer an indication of the size of these events. Therefore, multiple landslides of varying sizes may be affected by the same rainfall event but are reported as a single or unclear number of events. Finally, the reporting accuracy often varies significantly by region, country, province, and district. To some extent, this issue can be overcome when landslide events are considered at the national scale, but it remains a major problem when considering landslide reporting globally. Reports from specific countries may over or underestimate the impacts of 


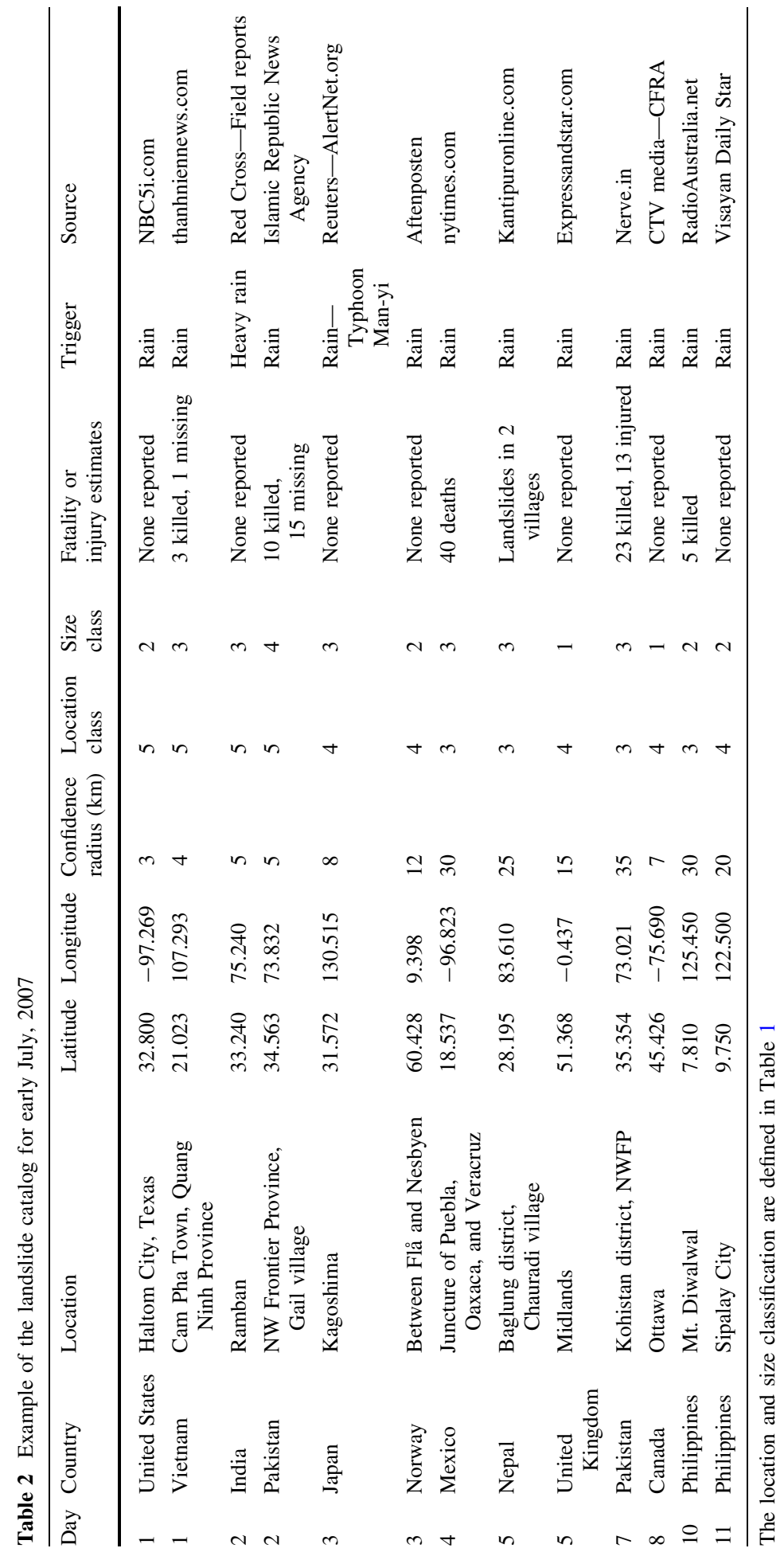


landslide events due to political factors or poor communication (Petley et al. 2007). Other important issues stem from only considering sources written in English. While many papers or international aid organizations cover disaster events globally in multiple languages, they are more likely to report larger events that have impacted more people. A multi-lingual search of literature and news sources would significantly improve the completeness and accuracy of the data.

A final issue with compiling a global catalog is the difficulty in obtaining landslide information from existing studies or nationally compiled country databases due to government restrictions or concerns on data sharing. Despite the data variability associated with different cataloging methodologies, it is vital that available landslide inventories and event information be available to the natural hazards community in order to better understand landslide impacts globally. At present, there is no international cooperation to assimilate, compile, or distribute landslide event information outside of documenting online news coverage. A collaboration of this nature would be valuable and may be accomplished through the partnership of countries' geological surveys or academic institutions.

The landslide catalogs developed in this study are additionally affected by the different times in which they were compiled, causing the availability of landslide information and access to reports to vary between years. Prior to the initiation of the landslide compilation project in mid-2007, the landslide inventories were primarily compiled from other databases and archived news reports which restricted the amount of information available to document the landslide events, particularly for smaller and less publicized events. However, after the project began, the landslide catalogs were assembled from near real-time news reports and were updated daily. As a result, the number of reports and impact information from the landslide events vary between the 3 years, with roughly 230 reports in the 2003 catalog, 400 reports in the 2007, and 550 reports in the 2008 catalog.

\section{Results of the current landslide catalogs}

\subsection{Spatial and temporal distribution}

While the landslide catalogs vary in the number of reports, the relative distribution, both spatially and temporally, remain consistent within the 3 years considered. Figure 2 illustrates the spatial distribution of landslide events globally for the 3 years. The 2003, 2007, and 2008 landslide catalogs have reported landslide events from 44, 60, and 67 countries, respectively, with an average number of fatalities per event ranging from 10 for 2003 to 4 people killed per event report for 2007 and 2008. Between $68 \%$ and $74 \%$ of the landslide reports have a radius of confidence within $25 \mathrm{~km}$ and the majority of events are described as having a size classification value of 3 .

The monthly frequency of reports and fatalities in the three catalogs indicate the greatest number of events occur between July and October, with a peak of reports in August (Fig. 3). The percentage of monthly fatalities is the highest in the mid-summer months, which is consistent with Petley et al. (2005), but also shows a peak of fatalities in March and November to December.

\subsection{Analysis of the landslide catalog}

In order to determine landslide density and impact regionally, the catalogs for the 3 years were divided according to eight regions. Figure 4 illustrates the number of reports and 

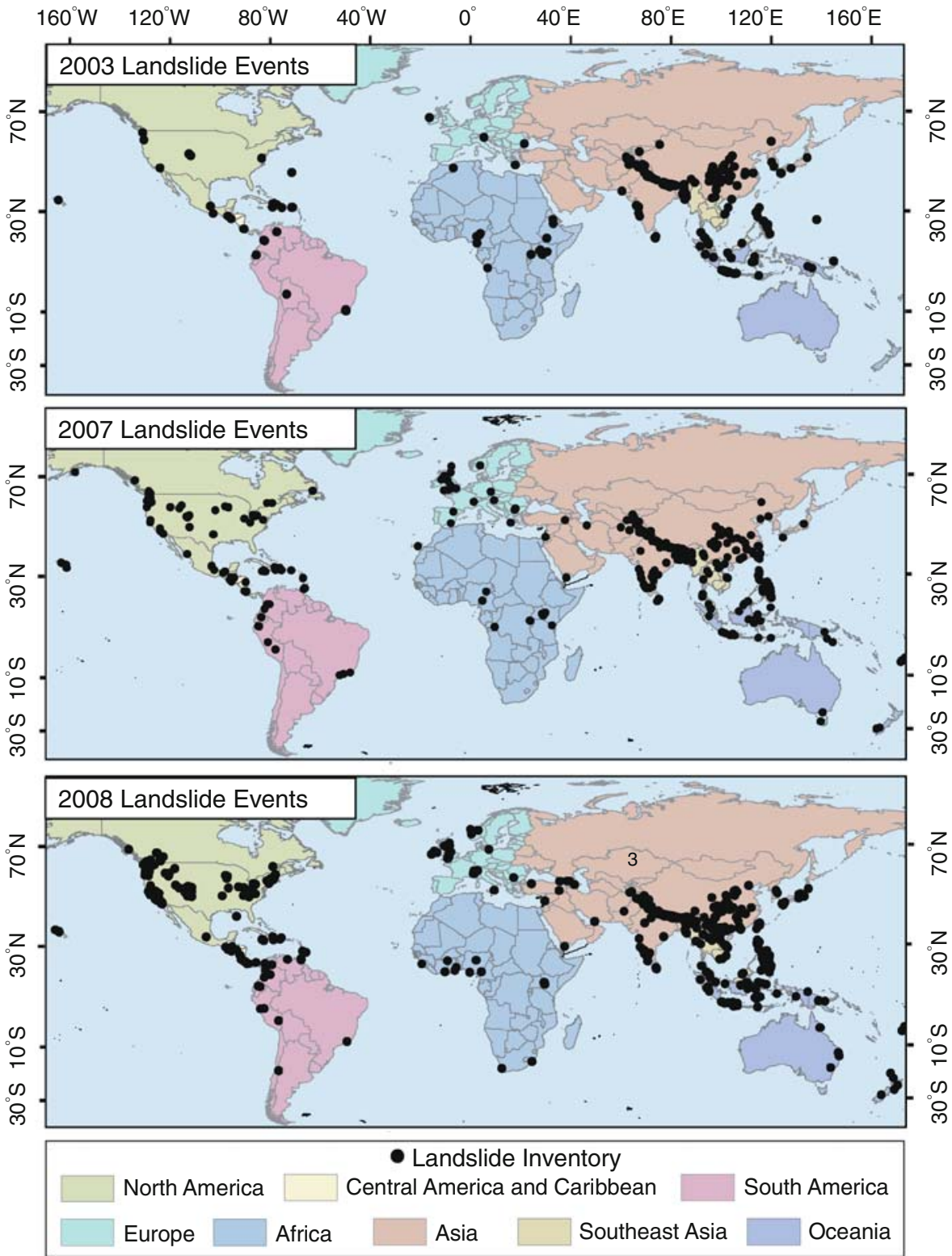

Fig. 2 Maps of landslide locations for the 3 years of the landslide catalog, shown according to geographic region

fatalities as a percentage of the total number according to region. Asia, particularly India, Nepal, China, and Japan, comprise the largest proportion of landslide reports and fatalities for all years considered. This region has the largest population by two orders of magnitude and the second largest land area (excluding Russia, which had no reports).

The fatalities from each region are further broken down by month. Figure 5 provides an example from 2008, but results are comparable for the other years. Asian reports and 
Fig. 3 Combined distribution of landslide reports and fatalities for 2003, 2007, and 2008 shown as a proportion of the total per month
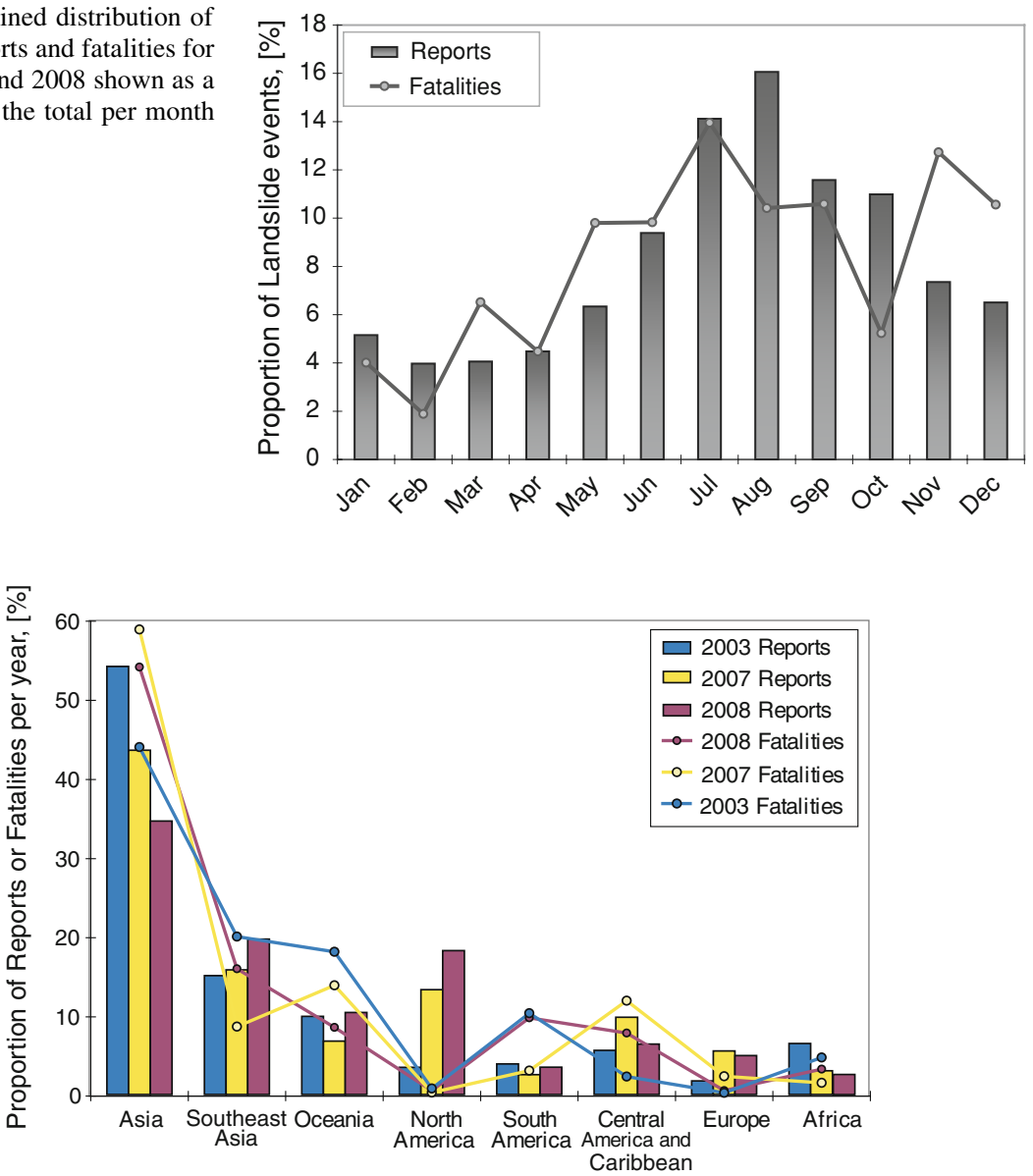

Fig. 4 Proportion of landslide reports and fatalities by region for the 2003, 2007, and 2008

fatalities dominate in the summer months during the monsoon season. Landslide reports in Southeast Asia, comprising the Philippines, Vietnam, Thailand, and others, have a consistent number of reports for each month but fatalities peak between June and November. The number of landslide reports and fatalities in Oceania is the highest between October and April, likely due to consistent heavy rainfall associated with the movement of the Inter-Tropical Convergence Zone. The Central American and Caribbean region have a high number of reports in the fall months, when tropical cyclones climatologies dominate. For the 2008 catalog, over $50 \%$ of the landslides reported in Asia, Africa, and South America had associated fatalities; Central America and the Caribbean, Oceania and Southeast Asia had reported fatalities for between $40 \%$ and $50 \%$ of the events. In contrast, North America recorded only $2 \%$ of events with fatalities.

The regional distribution in landslide reporting and fatalities is also evaluated on a country basis. Table 3 lists the 10 highest ranked countries in terms of percentage of landslide reports and landslide fatalities compared to the total number for each of the three landslide catalogs. For every year, the same six countries have the highest percentage of 
Fig. 5 Total number of landslide reports (a) and fatalities (b) for 2008 as a function of month and region
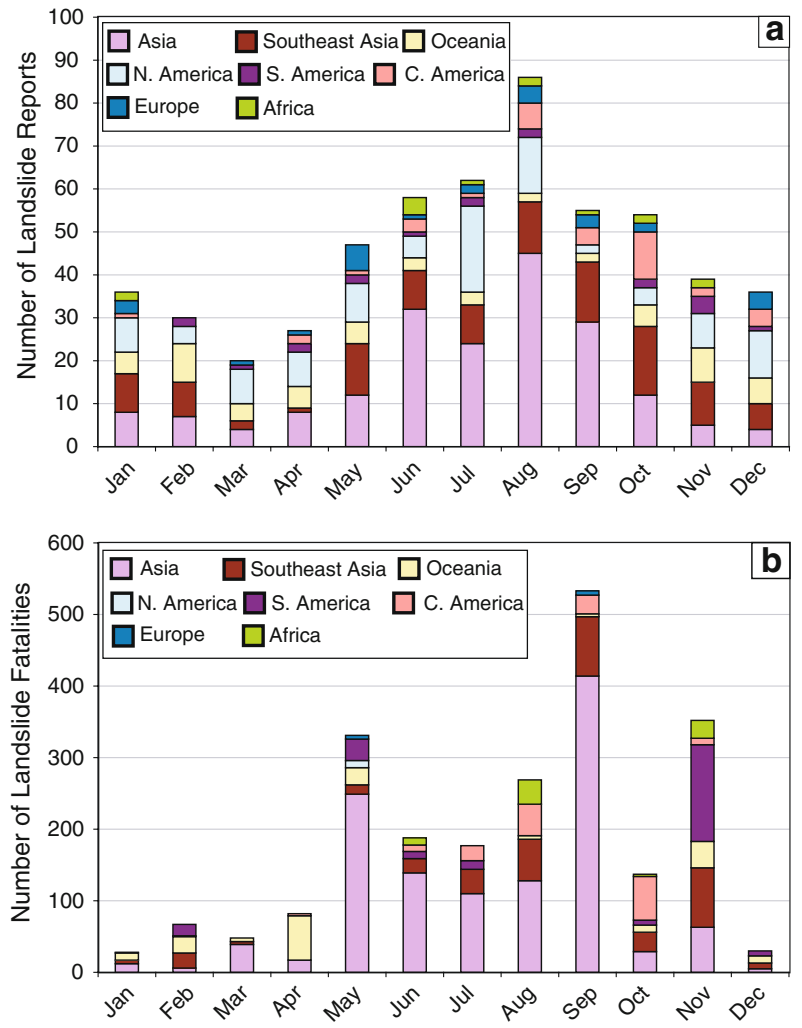

reports: India, China, Nepal, Indonesia, the Philippines, and the United States. The top ranked countries for the number of fatalities include India, China, Nepal, Indonesia, and the Philippines as well as countries where a small number of reported landslides have caused many fatalities.

\section{Discussion}

The evaluation of the three landslide catalogs is intended to illustrate the global distribution of landslide reports and fatalities as well as compare the relative accuracy and limitations of this methodology. Determining the geographic location of the landslide events, especially when they are associated with other hazard events, is very challenging and represents a large source of uncertainty when compiling the inventory.

There are many separate sources of variability that can influence the size and distribution of the catalog both naturally and artificially. Due to the limited temporal extent and completeness of the current landslide catalogs, it is unrealistic to accurately attribute modes of variability to specific sources. Information on the fatalities, number of reports, and regional distribution can vary markedly due to climate variability such as ENSO and monsoon cycles (Nagarajan et al. 2000; Ngecu and Mathu 1999). Differences in media coverage of landslide events and availability of online articles within different regions can also significantly influence the catalog of events and are much more difficult to quantify. 
Table 3 List of the top 10 countries with the highest percentage of landslide reports (top) and landslide fatalities (bottom) for the 3 years of the landslide catalog, shown as a percentage of the total reports for each year

\begin{tabular}{llrlrlr}
\hline Rank & Country & $2003(\%)$ & Country & $2007(\%)$ & Country & $2008(\%)$ \\
\hline \multicolumn{2}{l}{ Landslide reports } & & & & & \\
1 & Nepal & 18 & India & 18 & Nepal & 6 \\
2 & China & 15 & United States & 11 & China & 10 \\
3 & India & 13 & Philippines & 10 & India & 11 \\
4 & Indonesia & 9 & China & 9 & Indonesia & 7 \\
5 & Philippines & 6 & Nepal & 7 & Philippines & 10 \\
6 & United States & 3 & Indonesia & 4 & United States & 16 \\
7 & Vietnam & 3 & Pakistan & 2 & Vietnam & 4 \\
8 & Pakistan & 2 & Vietnam & 2 & Malaysia & 3 \\
9 & Malaysia & 2 & Tajikistan & 2 & Canada & 2 \\
10 & Bangladesh & 2 & Malaysia & 1 & Colombia & 2 \\
Landslide fatalities & & & & & \\
1 & Philippines & 18 & China & 19 & China & 35 \\
2 & China & 18 & Indonesia & 14 & Vietnam & 9 \\
3 & Indonesia & 18 & India & 10 & Indonesia & 8 \\
4 & Nepal & 11 & Bangladesh & 8 & India & 8 \\
5 & India & 7 & Pakistan & 8 & Brazil & 6 \\
6 & Bolivia & 5 & Afghanistan & 7 & Nepal & 5 \\
7 & Bangladesh & 4 & Dominican Republic & 5 & Philippines & 4 \\
8 & Kyrgyzstan & 2 & Philippines & 5 & Colombia & 3 \\
9 & Sri Lanka & 2 & Nepal & 4 & Haiti & 3 \\
10 & Uganda & 2 & Malaysia & 3 & Burma & 2 \\
\hline & & & & & \\
\hline
\end{tabular}

Petley et al. (2005) illustrates this variability with global landslide fatality estimates from 1980 to 2003, which range from less than 1,000 to over 3,000 deaths in two consecutive years. In addition, recording the landslide occurrences in near real-time provides significantly more media resources than collecting landslide event information retrospectively.

When considering individual years, extremely damaging landslides or a series of landslides set off by a single triggering event can skew the resulting analysis. Therefore, a country with only one or two events that kill many people may appear to have more extreme landslide hazard impacts than it would if multiple years were consulted, as evidenced in Table 3. In addition, countries with more consistent coverage, such as the United States, are likely to bias the statistics by the heightened availability of reports for smaller events which would likely not be cataloged elsewhere. Another source of uncertainty or bias in the landslide database which affects the classification of landslide sources and the inventory completeness is identifying landslide events that have multiple triggering sources. Effectively categorizing the primary sources of landslide initiation remains a challenging task due to limited information from existing landslide event reports. Future landslide cataloging efforts should work to include landslides triggered by all sources to more accurately characterize the spatial and temporal patterns of these hazards occurrence and source characteristics. This will allow for a more comprehensive analysis of landslide events globally and will greatly improve the landslide inventories. 


\section{Conclusions}

The methodology outlined in this article can serve as a framework to standardize global landslide event inventories and landslide event reporting, and can be applied at a variety of spatial scales. There are many organizations working to provide websites and databases with links to reports of landslide events worldwide. This methodology seeks to compile and translate these sources into an exploitable, easily obtained reference that can be used for evaluating general landslide trends, comparing results with other landslide inventories, and testing global landslide hazard studies. The landslide catalogs for the considered years vary in the number of reports, which can be attributed to the availability of accessing daily rather than archived landslide reports. Yet despite data variability, the general patterns of spatial and temporal distribution of landslide events and fatalities are surprisingly consistent between the 3 years. The results presented for the 3 years serve as the lower boundary for the total number of events occurring worldwide. The catalogs will continue to improve as the landslide events are updated daily, with increased access to a range of online and written news media and other reports.

This inventory is unique in its consideration of rainfall-triggered landslide events for all countries. It also emphasizes the importance of estimating the location accuracy, landslide size, and timing of the event in systematic ways, beginning with the effective and accurate communication of event information through media sources. These elements make the catalogs more useful for general landslide research and for evaluating global forecast tools that are being developed. We intend to continue work in compiling global landslide events, which will provide a better understanding of trends in landslide distribution, impact, and regional reporting biases. The catalogs can be further improved by considering multilingual reporting, integrating previous landslide inventory studies at the regional level, and communicating with government and aid agency officials to better quantify landslide impacts. Encouraging the exchange of available landslide information globally will also aid in consistent reporting and redundancy for detailing landslide events. While there are a number of limitations to this landslide inventory, it serves as an important foundation for enhancing our understanding of landslide hazards over larger areas and for testing hazard and susceptibility landslide studies at appropriate scales.

Acknowledgments The authors thank Lynne Shupp and Teddy Allen for their help in compiling and analyzing the landslide inventory information. This work was supported by the NASA Graduate Student Summer Program, NASA Earth Systems Science Fellowship, and NASA's Applied Sciences Program.

Open Access This article is distributed under the terms of the Creative Commons Attribution Noncommercial License which permits any noncommercial use, distribution, and reproduction in any medium, provided the original author(s) and source are credited.

\section{References}

Ardizzone F, Cardinali M, Carrara A, Guzzetti F, Reichenbach P (2002) Impact of mapping errors on the reliability of landslide hazard maps. Nat Hazards Earth Syst Sci 2:3-14

Baeza C, Corominas J (2001) Assessment of shallow landslide susceptibility by means of multivariate statistical techniques. Earth Surf Process Landf 26:1251-1263. doi:10.1002/esp.263

Baum RL, Savage WZ, Godt JW (2002) TRIGRS - a Fortran program for transient rainfall infiltration and grid-based regional slope-stability analysis. USGS Open-file Report 02-424

Castellanos Abella EA, van Westen CJ (2007) Generation of a landslide risk index map for Cuba using spatial multi-criteria evaluation. Landslides 4:311-325. doi:10.1007/s10346-007-0087-y 
Chau KT, Sze YL, Fung MK, Wong WY, Fong EL, Chan LCP (2004) Landslide hazard analysis for Hong Kong using landslide inventory and GIS. Comput Geosci 30:429-443. doi:10.1016/j.cageo.2003. 08.013

Crozier MJ, Glade T (2006) Landslide hazard and risk: issues, concepts and approach. In: Glade T, Anderson MG, Crozier MJ (eds) Landslide hazard and risk. Wiley, West Sussex, pp 1-40

Diaz VJ (1992) Landslides in the squatter settlements of Caracas; towards a better understanding of causative factors. Environ Urban 4:80-89. doi:10.1177/095624789200400208

Guzzetti F (2000) Landslide fatalities and the evaluation of landslide risk in Italy. Eng Geol 58:89-107. doi: 10.1016/S0013-7952(00)00047-8

Guzzetti F, Cardinali M, Reichenbach P (1994) The AVI project: a bibliographical and archive inventory of landslides and floods in Italy. Environ Manag 18:623-633. doi:10.1007/BF02400865

Guzzetti F, Carrara A, Cardinali M, Reichenbach P (1999) Landslide hazard evaluation: a review of current techniques and their application in a multi-scale study, Central Italy. Geomorphology 31:181-216. doi: 10.1016/S0169-555X(99)00078-1

Haigh MJ, Rawat JS, Rawat MS, Bartarya SK, Rai SP (1995) Interactions between forest and landslide activity along new highways in the Kumaun Himalaya. For Ecol Manag 78:173-189. doi:10.1016/ 0378-1127(95)03584-5

Hong Y, Adler R, Huffman G (2006) Evaluation of the potential of NASA multi-satellite precipitation analysis in global landslide hazard assessment. Geophys Res Lett 33:L22402. doi:10.1029/2006GL 028010

Hong Y, Adler R, Huffman G (2007) Use of satellite remote sensing data in the mapping of global landslide susceptibility. J Nat Hazards 43:245-256. doi:10.1007/s11069-006-9104-z

Iverson RM (2000) Landslide triggering by rain infiltration. Water Resour Res 36:1897-1910. doi:10.1029/ 2000WR900090

Kirschbaum DB, Adler R, Hong Y, Lerner-Lam AL (2009) Evaluation of a satellite-based landslide algorithm using global landslide inventories. Nat Hazards Earth Syst Sci 9:673-686

Larsen MC, Parks JE (1997) How wide is a road? The association of roads and mass-wasting in a forested montane environment. Earth Surf Process Landf 22:835-848. doi:10.1002/(SICI)1096-9837(199709) 22:9<835::AID-ESP782>3.0.CO;2-C

Marui H, Nadim F (2009) Landslides and multi-hazards. In: Sassa K, Canuti P (eds) Landslides—disaster risk reduction. Springer, Berlin, pp 435-450

Nagarajan R, Roy A, Vinod Kumar R, Mukherjee A, Khire MV (2000) Landslide hazard susceptibility mapping based on terrain and climatic factors for tropical monsoon regions. Bull Eng Geol Environ 58:275-287. doi:10.1007/s100649900032

Ngecu WM, Mathu EM (1999) The El-Nino-triggered landslides and their socioeconomic impact on Kenya. Environ Geol 38:277-284. doi:10.1007/s002540050425

Petley DN, Dunning SA, Rosser NJ (2005) The analysis of global landslide risk through the creation of a database of worldwide landslide fatalities. In: Hungr O, Fell R, Counture R, Ebergardt E (eds) Landslide risk management. Balkema, Amsterdam, pp 367-374

Petley DN, Hearn GJ, Hart A, Rosser NJ, Dunning SA, Oven K, Mitchell WA (2007) Trends in landslide occurrence in Nepal. Nat Hazards 43:23-44. doi:10.1007/s11069-006-9100-3

van Westen CJ, van Asch TWJ, Soeters R (2006) Landslide hazard and risk zonation-why is it still so difficult? Bull Eng Geol Environ 65:167-184. doi:10.1007/s10064-005-0023-0 